\title{
CRYSTALLOGRAPHIC CHARACTERISATION OF CELLULOSE NANOWHISKERS FROM OIL PALM FIBRE WASTE
}

Souza, N. F. . ,*; Pinheiro, J. A. ${ }^{2}$; Vasconcelos, N. F. ${ }^{1}$; Rosa, M. F. ${ }^{3}$; Morais, J. P. S. ${ }^{3}$; Cassales, A. R. ${ }^{3}$; Filho, M. S. M. S. ${ }^{3}$

${ }^{1}$ Universidade Federal do Ceará, Departamento de Eng. Química-UFC, Fortaleza, Brasil

2 Instituto Federal do Ceará, Departamento de Processos Químicos- IFCE, Fortaleza, Brasil

${ }^{3}$ Embrapa Agroindústria Tropical, Fortaleza, Brasil.

*nagila.pr@hotmail.com

The aim of this work was to extract cellulose nanocrystals (CNC) from oil palm mesocarp fibres by ecofriendly pulping pathways. The fibres were treated by acetosolv pulping and peroxide bleaching prior to nanostructure extraction by $\mathrm{H}_{2} \mathrm{SO}_{4} 72 \%(\mathrm{w} / \mathrm{w})$ hydrolysis. CNC were obtained as described at table 1 . CNC were freeze-dried and analyzed in a Rigaku diffractometer model DMAXB, Cu tube, wavelength of $1.54 \AA$, operating at $40 \mathrm{kV}$ and $30 \mathrm{~mA}$, between $2 \theta$ angle from $10^{\circ}$ to $45^{\circ}$. The crystallinity index (CI\%) was calculated as described by Segal et al. [1]. Table 1: Reaction conditions and crystallinity index of the oil palm pressed mesocarp fibres

\begin{tabular}{|c|c|c|c|}
\hline CNC & Temperature $\left({ }^{\circ} \mathrm{C}\right)$ & Time $(\mathrm{min})$ & CI (\%) \\
\hline 1 & 45 & 20 & 70.7 \\
\hline 2 & 45 & 120 & 64 \\
\hline 3 & 28 & 70 & 70 \\
\hline 4 & 62 & 70 & 60.3 \\
\hline
\end{tabular}

Only typical cellulose I peaks were noted in the diffraction pattern at $15.6^{\circ}$ and $22.7^{\circ}$. The absence of a double peak at $22.0^{\circ}$ is an evidence of no cellulose II. Higher CI in the samples 1 and 3 indicates an optimization in the hydrolysis process, with reduction of the temperature or of the reaction time. The higher the CI, the higher the crystalline fraction of the nanostructures, resulting in better mechanical and thermal properties. Thus, the chemical pulping allowed CNC isolation with high crystallinity and similar structure to the native cellulose in oil palm.

[1] SEGAL et al., Text. Res. J., 29(10), p.786-794, 1959. 